\title{
O olhar francês sobre o Nuevo Cine Latinoamericano
}

\author{
Mariana Martins Villaça ${ }^{1}$
}

Resumo:

Neste artigo analisamos as principais motivações - políticas e culturais - que levaram a crítica cinematográfica francesa a se voltar ao cinema latino-americano, especialmente às obras dos cineastas empenhados em explorar as temáticas sociais e preocupados com a conscientização política do público, no período compreendido entre o final dos anos 1960 e meados dos anos 1970. A partir da análise das revistas Positif e Cahiers du Cinéma, buscamos problematizar a importância da crítica francesa no processo de consolidação do movimento denominado nuevo cine latinoamericano. Além disso, procuramos apresentar algumas discussões sobre o "cinema político" desenvolvidas por essas revistas e refletir acerca dos limites, das peculiaridades e da própria repercussão, deste lado do Atlântico, do "olhar francês" sobre o cinema da América Latina.

Palavras-chaves: nuevo cinema latinoamericano, cinema político, revistas francesas

\footnotetext{
1 Doutora em História pela Universidade de São Paulo. Professora de História da América na Universidade Federal de São Paulo. End. Acadêmico: Estr. do Caminho Velho, 333, Bairro dos Pimentas; Guarulhos - SP, CEP. 0752-312. Email: marimavi@hotmail.com
} 
No final dos anos 1960, as revistas francesas especializadas em cinema se abriram ao cinema latino-americano e passaram a incluir esse tema nas discussões acerca do "cinema político", ou melhor, do tratamento conferido, pelo cinema moderno, aos temas sociais e políticos -, discussões essas que já vinham acontecendo desde os anos 1950. Nessa época, muitos cineastas latino-americanos, preocupados em realizar obras que denunciassem a realidade social e política da região, discutiam fervorosamente a necessidade de defender um movimento cinematográfico em torno do que chamavam de Nuevo Cine Latinoamericano, buscando precisar quais seriam seus princípios e características ${ }^{2}$.

Cabe esclarecer que, em termos conceituais, Nuevo Cine Latinoamericano ou NCL (sigla comumente usada pela historiografia, e que também adotaremos nesse trabalho) é uma expressão que denomina, de forma pouco precisa, certa produção cinematográfica, documental e ficcional, realizada na América Latina, principalmente a partir de 1967, geralmente de forte teor político e social. Essa expressão surgiu concomitantemente no discurso de alguns realizadores e na imprensa especializada, na América Latina, no final dos anos sessenta, e foi logo endossada por realizadores de diversas nacionalidades e inclinações políticas, com estilos muito variados de pensar e de fazer cinema. No final dos anos sessenta, essa terminologia foi bastante difundida, dentro e fora da América Latina, e passou a designar um suposto movimento cinematográfico que, no entanto, sempre se mostrou extremamente plural e de difícil mapeamento, ainda que muitos de seus protagonistas identificassem como eixo fundamental a preocupação com a realidade latino-americana e com estratégias de conscientização política do público. Assim, podemos afirmar que o $N C L$ se tornou, sobretudo, uma "idéia-força" em torno da qual se alinharam diversos projetos estéticos e ideológicos (alguns nacionais, envolvendo grupos locais de cineastas, outros autorais, individuais), no final dos anos sessenta. Ao longo dos anos 70 e 80, alguns desses projetos foram abandonados, substituídos ou transformados, mas houve uma notável permanência, até dos dias de hoje, do termo Nuevo Cine Latinoamericano e de alguns

\footnotetext{
${ }^{2}$ Abordamos esse tema em nossa pesquisa de pós-doutorado, intitulada "Circuitos e diálogos do Nuevo Cine Latinoamericano (1967-1986)", da qual esse artigo é um desdobramento. Esta pesquisa foi desenvolvida com apoio da Fapesp, junto ao Departamento de História da FFLCH-USP, sob a supervisão da Profa. Dra. Maria Ligia Coelha Prado, no período 2007-2009.
} 
princípios a ele identificados, ainda que a produção cinematográfica assim designada se modificasse substancialmente no decorrer desse período ${ }^{3}$.

Neste artigo, analisamos o foco desse interesse da crítica francesa na América Latina, identificando as principais motivações - políticas e culturais - que imperaram numa espécie de "onda latino-americanista" que assolou o meio cinematográfico europeu. Analisamos também a maneira pela qual essa produção cinematográfica foi avaliada, problematizando os critérios utilizados por essas revistas e refletindo acerca dos limites, peculiaridades e da repercussão, neste lado do Atlântico, desse "olhar francês" sobre a América Latina.

Refletir sobre as impressões e avaliações formais do cinema latino-americano por parte da crítica cinematográfica francesa nos possibilita discutir uma tese bastante reiterada pela historiografia sobre cinema e pelos testemunhos ou balanços (de caráter memorialista, em geral) publicados sobre o tema, a saber: a afirmação de que o reconhecimento pela crítica estrangeira (entenda-se européia) de que havia um movimento cinematográfico original, "autêntico", latino-americano, foi fundamental para a configuração da própria idéia de movimento na América Latina, como se nota na seguinte afirmação: “(...) é em relação ao público e à crítica européia que os cineastas latino-americanos começam a formular e sistematizar as suas idéias sobre o NCL enquanto movimento subcontinental" [grifos nossos]. (NÚÑEZ, 2009, p. 21)

Discordamos, portanto, dessa proposição e de outras semelhantes, como as formuladas por críticos e historiadores do cinema como Zuzana Pick, que afirmam que os movimentos cinematográficos latino-americanos foram identificados na Europa, no início dos anos sessenta, antes que eles próprios se reconhecessem como tais (PICK, 1996, p. 17). Partimos da hipótese de que o processo de afirmação do $N C L$ - não desconsiderando que a crítica européia teve grande importância - é complexo e teve como vetor fundamental um grande esforço dos próprios cineastas latino-americanos para serem reconhecidos, aqui na América Latina, como parte de um grupo esteticamente renovador e portador de uma proposta de esquerda, antiimperialista, que legitimava sua identidade em contraposição a cineastas e eventos de grande prestígio em nosso mercado, mas sem preocupações sociais e políticas, e muito colados a modelos

\footnotetext{
${ }^{3}$ O Festival Internacional Del Nuevo Cine Latinoamericano (FINCL) realizado anualmente em Havana, desde 1979, e a Fundación del Nuevo Cine Latinoamericano, sediada nessa mesma cidade desde 1985 são instituições que contribuem para a perpetuação do uso do termo e a consolidadção de determinada memória do NCL.
} 
provenientes do cinema norte-americano e europeu. Verificamos que essa versão de que a crítica estrangeira "consolidou" o $N C L$ também foi proferida na época, por cineastas e críticos latino-americanos que tinham o objetivo de fazer crer que o $N C L$ já fazia enorme sucesso no exterior, em contraposição ao pouco prestígio que detinha aqui na América Latina, por parte do público, dos distribuidores e dos organismos financiadores. Houve, portanto, uma estratégia de valorização, de propaganda, com a pretensão de divulgar que "o mundo já se curvava diante do $N C L$ ". Ainda que, de fato, muitos filmes latino-americanos tenham sido premiados e tenha havido uma significativa disposição, por parte da crítica européia, em destacar e valorizar os novos talentos latino-americanos (principalmente no período entre meados dos anos 60 a meados dos anos70), essa perspectiva de que lá houve a identificação e o reconhecimento de um movimento autêntico e de âmbito continental não nos pareceu clara nas fontes que pesquisamos, como procuraremos demonstrar. Acreditamos que a valorização dos "novos cinemas" da América Latina, no plural (e não "do" $N C L$ ), deve ser compreendida como mais um fator que contribuiu para a afirmação desse "movimento". Assim, neste trabalho, iremos adentrar os interesses da crítica européia nessa inclinação (temporária e limitada) ao cinema latino-americano, e focaremos alguns fatores que nos parecem cruciais para explicar essa aproximação, como a intensa politização do meio intelectual francês, nessa época, e a necessidade da crítica francesa em reconhecer possíveis "afilhados" de sua própria cinematografia, do outro lado do Atlântico, a fim de celebrar a tradição e a qualidade do cinema francês, num contexto de grande crescimento e popularização do cinema norte-americano.

Tomamos como fontes duas revistas de ampla circulação e grande prestígio no meio cinematográfico europeu, Cahiers du Cinéma e Positif. Lembremos que a França, nesse momento, era um grande manancial de formulações teóricas e de discussões estéticas e políticas acerca do cinema moderno e contemporâneo. Entre essas duas revistas, nos deteremos mais minuciosamente em Positif, publicação que se definia como "de esquerda" e rivalizava com a prestigiada Cahiers du Cinéma, revista que também dedicou alguns artigos ao cinema latino-americano, ao longo de sua existência, mas em muito menor número que Positif, como veremos. Antes de analisarmos a cobertura que o cinema latino-americano recebeu nessas publicações, cabe fazer uma breve apresentação desses periódicos.

A revista Positif foi criada em 1952, um ano depois da fundação de Cahiers $d u$ Cinéma (cujo número 1 é de abril de 1951), originalmente na cidade de Lyon, por 
Bernard Chardère. Logo foi transferida a Paris, em busca de mercado mais amplo, onde procurou afirmar sua postura esquerdista e entrou em choque, em diversos momentos, com Cahiers du Cinéma, por questões principalmente políticas, mas que envolviam outras problemáticas: conflitos geracionais, legitimação de certas tendências ou diretores, afirmação de poder no meio cinematográfico, dentre outros fatores.

Positif e Cahiers nutriram disputas por público, prestígio e por espaço no mercado editorial e no meio cinematográfico francês, desde seu surgimento. Essas disputas se arrastaram durante décadas e se manifestaram em choques de posições políticas, provocações e réplicas publicadas em ambas as revistas e, de forma indireta, em lutas travadas em diversos outros espaços do meio cinematográfico. Ambas concorriam na cobertura dos festivais, na arregimentação de colaboradores e na realização de mostras de cinema. (AMIOT-GUILLOUET, 2004, pp. 43-61)

Sobre essas mostras, cale esclarecer que, a partir do final dos anos 1960, estas duas revistas passaram a organizar, separadamente (e como concorrentes), mostras ocasionais geralmente aproveitando salas de exibição voltadas aos chamados cinema "de autor" ou filmes "de arte", acompanhando uma tendência já disseminada na França. Em Paris, especialmente, não apenas revistas especializadas em cinema organizavam mostras: havia, na capital, as semanas das Lettres Françaises, da Tribune Socaliste e diversas outras. (THIRARD, 1969, pp. 52-54) Nessa empreitada, a revista Cahiers $d u$ Cinéma saiu na frente, a após o sucesso obtido com sua mostra, Positif também passou a organizar suas semanas e quinzenas, em parceria o Cine Club Action.

As mostras organizadas pelas duas revistas foram, juntamente com os festivais europeus $^{4}$, muito importantes para a divulgação do cinema latino-americano de cunho político, e não apenas pelo que de fato era exibido: o que era previamente anunciado mas, por diversas razões, não se exibia, despertava também grande curiosidade por parte do público e da crítica. Esse foi o caso do filme argentino La hora de los hornos (1968) do Grupo Cine Liberación, encabeçado por Fernando Solanas e Octavio Getino,

\footnotetext{
${ }^{4}$ Destacamos, na Itália, as cinco "Rassegnas del cinema latino-americano", organizadas pela instituição cultural Columbianum, no início dos anos sessenta e as Mostras Internazionales del "Cinema Nuovo", mais conhecidas como Festivais de Pesaro, a partir de 1965. Além destes, foram importantes difusores do cinema latino-americano o Festival de curtas de Oberhausen, o Festival de Berlim, os Festivais de Cannes (principalmente a partir de 1962),o Festival Cinématographique International de Paris, o Festival International du film de court métrage et du film documentaire, em Lille, e o Festival de Biarritz, todos nos anos setenta. Nos anos oitenta, ganham destaque o Festival Cinématographique International des Trois Continents de Nantes (desde 1981) e os Rencontres des Cinémas d'Amérique latine, que deram origem ao Festival de Toulouse (desde 1989).
} 
previsto para ser exibido na Quinzena organizada pela Positiv em janeiro de 1969, mas que sofreu censura por parte dos donos das salas parisienses, preocupados com o incandescente entusiasmo com que o público estudantil vinha recebendo a obra, nos festivais europeus. (LIMA, 2008, )

Assim, considerando todas as ações culturais protagonizadas por essas revistas, podemos considerá-las, como sugere Jean-François Sirinelli, importantes centros de "fermentação intelectual" em torno dos quais jornalistas, críticos, cineastas e aficcionados por cinema, em geral, tecem redes de sociabilidade e compartilham determinada cultura política. (SIRINELLI, 1996)

Nesse contexto, Positif e Cahiers du Cinéma direcionaram seu olhar para a América Latina num momento em que a presença da indústria cinematográfica norteamericana era vista como nefasta, na França. Havia uma valorização, portanto, de todo tipo de produção que mais se aproximava do "cinema de autor" e do modelo francês: nesse sentido, a crítica valorizava o neorrealismo, o free cinema e buscava os ecos da influência francesa na América Latina. É essa perspectiva que orienta boa parte dos artigos e resenhas sobre o cinema latino-americano na França. Em geral, esses trabalhos reconhecem qualidades no novo cinema latino-americano e elegem como "núcleo duro" de toda essa produção, o Cinema Novo brasileiro, considerado indiscutivelmente, pelas equipes de colaboradores, a expressão cinematográfica mais criativa e de melhor qualidade na América Latina. Assim, há o reconhecimento de uma nova tendência criativa do cinema latino-americano, porém localizada em nichos específicos: enquanto o cinema brasileiro é muito valorizado, por exemplo, há flagrante descaso, principalmente nos Cahiers, com a cinematografia cubana, considerada muito panfletária, a despeito de haver, dentre os inúmeros cineastas cubanos, diversos diretores responsáveis por um cinema sofisticado e crítico ao socialismo, na Ilha. $\mathrm{O}$ cinema cubano só foi foco de um artigo exclusivo de Cahiers, pela primeira vez, em 1997.

Em relação a essa publicação, a pesquisadora francesa Julie Amiot-Guillouet fez um balanço da presença da América Latina em Cahiers e afirmou que essa ocorreu principalmente entre o início dos anos sessenta até 1973. Ainda assim, é preciso esclarecer que a quantidade média de artigos voltados ao cinema latino-americano, desde seu surgimento, sempre foi bem pequena. Há mais artigos sobre o cinema da Ásia (25 artigos, até 2003) do que sobre a América Latina (22 artigos, até esse mesmo ano), por exemplo. (AMIOT-GUILLOUET, 2004) 
Segundo pudemos verificar, o período de maior interesse pelo cinema latinoamericano se concentrou entre o final dos anos sessenta a meados dos anos setenta, dado que também se repete no caso de Positif. Nessa fase, Cahiers publicou dossiês dedicados ao Brasil (Núm. 176, março 1966, 11 págs) e aos seguintes diretores : Glauber Rocha (1969), Jorge Sanjinés, Fernando Solanas (1969) e Cacá Diegues (1970).

Cahiers sempre teve um grande poder simbólico no meio cinematográfico internacional: uma crítica publicada nessa revista tinha o status de "a crítica francesa". Segundo a opinião de vários diretores latino-americanos, entretanto, essa crítica era geralmente marcada pela superficialidade, alguma condescendência e certas comparações, nem sempre procedentes, com o cinema soviético. Segundo o cineasta baiano Glauber Rocha, Cahiers era símbolo de um certo academicismo nefasto para o cinema latino-americano, uma vez que, junto com o Festival de Cannes configurava um "sistema" onde todos os jovens cineastas queriam ser admitidos e reconhecidos.

Cabe destacar que apesar do Festival de Cannes oferecer um espaço limitado ${ }^{5}$ ao cinema do "terceiro mundo", o significado simbólico e a repercussão comercial de um filme exibido na Seleção oficial - e premiado - no festival, eram enormes, nos anos $60 \mathrm{e}$ 70. A partir de 1962, a Semaine Internationale de la Critique Française (criada no $14^{\circ}$ Festival de Cannes) passou oferecer a oportunidade para que os cineastas fora da seleção oficial mostrassem seus primeiros ou segundos filmes. Essa mudança foi em parte propiciada pelas novas discussões trazidas pela Nouvelle Vague, que contestavam o cinema comercial e propunha a valorização de cinematografias “minoritárias”.(RUEDA, 2004, pp.87-104)

Cannes sempre foi um alvo na mira dos cineastas latino-americanos, e alguns deles conseguiram espaço na mencionada Semaine. Por ela passaram os seguintes filmes do NCL: o boliviano Ukamau (1967), que suscitou, após essa exibição, a publicação nos Cahiers du Cinéma, do dossiê "Cinéma anti-impérialiste en Amérique latine"; o argentino La hora de los hornos, em 1969, que foi recebido com entusiasmo pelo público e pela crítica de esquerda ${ }^{6}$, e o chileno La tierra prometida, de Miguel Littín, em 1974, dentre alguns outros.(TOUBIANA, 1974, p.23)

\footnotetext{
${ }^{5}$ Na edição do Festival, de 1979, 7 filmes eram do "terceiro mundo", 10 dos países do Leste Europeu e 51 da Europa Ocidental e dos Estados Unidos. (PARANAGUÁ, 1980, pp. 58-63).

${ }^{6}$ Ver comentários de Louis Marcorelles, em Cahiers du Cinéma, núm. 210, mars 1969, p. 39
} 
A partir de 1969 o espaço destinado às cinematografias periféricas, em Cannes, sofreu um pequena ampliação com a criação, por parte da SRF (Société des Réalisateurs de Films) da sessão paralela La Quinzaine des Réalisateurs, da qual o cineasta venezuelano Atahualpa Lichy participou da organização desde seu início até 1975. Nessa sessão a participação da América Latina foi significativa até 1974, com cerca de 20 filmes por ano. Após essa data o número caiu abruptamente, para apenas 2 ou 3.

No geral, nos anos sessenta ou nos setenta, os filmes aparecem como objeto de resenha, nas revistas, somente após terem participado de algum grande festival, como Cannes, e ter agradado satisfatoriamente o júri. Seguindo essa lógica, são publicados por Positif artigos elogiosos à Batalha do Chile, de Patricio Guzmán ${ }^{7}$, A Última Ceia, de Tomás Gutiérrez Alea ${ }^{8}$ e Los Hijos de Fierro , de Fernando Solanas ${ }^{9}$.

As transformações ocorridas no Festival de Cannes, em benefício do cinema do “Terceiro Mundo", têm relação com a concorrência existente entre os festivais europeus de maior prestígio no período, bem como às pressões decorrentes das mudanças de conjuntura política na França. No início dos anos 70, por exemplo, as revistas francesas de cinema fazem severas críticas aos festivais de Veneza e de San Sebastian ${ }^{10}$, por estes serem politicamente conservadores e terem aderido ao "comércio e à mundanidade". Destaque para uma verdadeira mobilização das revistas Cahiers du Cinéma, Cinéma 71, Jeune Cinéma e Positif contra a nomeação do Gian-Luigi Rondi para a direção do Festival, em 1971 (por ser fascista) ${ }^{11}$

Assim, percebemos que as revistas de cinema exerceram papel importante ao pressionar para que o festival de Cannes se abrisse às novas produções em todo o mundo e oferecessem oportunidade para que tais filmes pudessem chegar ao circuito comercial. Nessa “campanha", Positif teve papel de destaque ${ }^{12}$. Essa publicação, na

\footnotetext{
7 THIRARD, Paul-Louis. “De l'Histoire, déjà (La Bataille du Chili)”. Positif, núm. 190, février 1977, pp. 68-69.

8 AMENGUAL, B. \& JORDAN, Isabelle. "Festival de Berlin 1978". Positif, núm. 207, juin 1978, pp. $52-57$.

9 AMENGUAL, Barthélemy, et al. "Le Festival de Cannes 1978”. Positif, núm. 208-209, juillet-aout 1978, p.88.

${ }^{10}$ BORDE, Colette. "San Sebastian 1970”. Positif núm. 120, octobre 1970, pp. $43-47$; TÖRÖK, JeanPaul. "Le martyre de San Sebastian". Positif núm. 134, janvier 1972, pp. 29-34.. CIMENT, Michel. "Venise, 1970", Positif, núm. 121, novembre 1970, pp. 8-21.

11 “L’Affaire Venise”. Positif núm. 132, novembre 1971, pp. 59-62.

${ }^{12}$ Num artigo de 1969, Michel Ciment e Bernard Cohn destacam a importância da Semaine de La critique e lamentam o fato de que a maioria dos filmes exibidos nessa sessão de Cannes provavlemente
} 
época, se mostrava uma fervorosa entusiasta de festivais "de esquerda" como o festival de curtas de Oberhausen ou o Festival de Berlim ${ }^{13}$, por abrirem-se gradativamente à produção latino-americana (principalmente em se tratando da sessão Fórum do Cinema Jovem, em Berlim). Ao mesmo tempo, criticava severamente a mudança de identidade do Festival de Locarno, em 1971 - evento que até então se configurara como um espaço para o cinema político - fruto da mudança de orientação da política cultural do governo suíço, alertando para o fato de que, em cerca de dois anos, "o cinema de combate havia perdido um dos seus raros refúgios" ${ }^{\prime 14}$.

Nesse sentido, vemos que Positif, mais que Cahiers, se interessou em registrar e avaliar as novas cinematografias latino-americanas. Isso se compreende pois, como mencionamos anteriormente, Positif sempre se afirmou como uma revista "de esquerda", uma alternativa a Cahiers. Por outro lado, seu surgimento e seu discurso também surtiram impacto na publicação concorrente pois o meio cinematográfico francês, e a própria equipe editorial de Cahiers encontrava-se dividida, simplificadamente, entre uma postura mais politizada e outra mais "formalista" na maneira de encarar a "sétima arte".

Vale a pena abrirmos um parêntese para abordar os efeitos da politização do meio intelectual francês em Cahiers e que contribuem para compreender o êxito de Positif ao consolidar um espaço no mercado editorial, bem como entender a própria natureza do interesse dessas publicações pela América Latina.

No final dos anos 1950, as preocupações em analisar o cinema (e a arte, bem como o papel do artista e do intelectual) do ponto de vista político, tomavam conta da intelectualidade francesa de um modo geral, uma vez que existia nessa época um bom número de intelectuais influentes, simpáticos ou filiados ao Partido Comunista Francês (como Jean Paul Sartre, Simone de Beauvoir, Merleau-Ponty, Albert Camus, dentre outros). Essa disposição provocou polêmicas dentro da revista Cahiers du Cinéma.

não conseguiria ir para circuito comercial. CIMENT, Michel et COHN, Bernard. "La VIIIe Semaine de la Critique". Positif, núm. 107, été 1969 (juilllet-aout), pp. 45-56.

${ }^{13}$ NIOGRET, Hubert. “Oberhausen 1970”. Positif núm. 120, octobre 1970, pp. 48-50; COHN, Bernard. "Deux genres, un troisiéme et quelques autres films à Oberhausen”. Positif, núm. 130, sept. 1971, pp. 3943. PÉREZ, Michel. "Berlin 70, une revolution de cuisine". Positif, núm. 121, novembre 1970, pp. 5256.; NIOGRET, Hubert. “Les deux Berlin”. Positif, núm. 144-145, novembre-decembre 1972, pp. 73-78.

${ }^{14}$ SEGUIN, Louis. "La fin de Locarno" Positif, num. 124, fevrier 1971, pp. 50-55. 
Movidos por questões ideológicas, dois grupos de colaboradores se aglutinaram em torno de dois críticos prestigiados que compunham a equipe da revista: George Sadoul (filiado ao Partido Comunista Francês) e André Bazin (de tendência católica e com preocupações formalistas em relação ao cinema), que reuniu em torno de si um grupo de jovens críticos, mais interessados nas discussões estéticas, conhecidos como "os jovens turcos" $" 15$. Foi o segundo grupo o que acabou predominando e dando o tom da revista (o que resultou na saída de Georges Sadoul. Dessa forma, o aparecimento de Positif e a própria seleção dos temas abordados pretendiam ser um efetivo contraponto à visão "alienada" vencedora em Cahiers.

No final dos anos 60, os Cahiers, sob o impacto de acontecimentos como o Maio de 68, sofreram um processo de politização - ou, para sermos mais específicos, "esquerdização". As cinematografias periféricas passaram a ser mais contempladas e alguns diretores como Antonioni, Rosselini, deixaram de ser tão cultuados. Isso ocorreu após outra cisão de sua equipe de redação, que repercutiu de forma intensa em seu público leitor, em geral não muito afeito ao cinema "político" e mais interessado nas discussões em torno do cinema “arte”. Essa segunda cisão, em 1963, se deu em função da formação de dois grupos, no interior da revista: um grupo que pretendia manter a revista como uma espécie de porta-voz da Nouvelle Vague (e que se organizou em torno de Jacques Rivette) e outro que preferia mantê-la independente, sem compromisso com determinada tendência, fazendo da revista uma defensora do cinema de autor, de forma ampla (e que se formou em torno de Eric Rohmer, editor-chefe da revista). ${ }^{16}$

As discussões em torno da identidade da revista resultaram em algumas modificações que a tornaram, no final dos anos 60, menos formalista: passou a valorizar a visão histórica nas análises das cinematografias, houve maior esforço dos colaboradores em compreender melhor os aspectos nacionais envolvidos nas produções cinematográficas e procurou-se evitar os enfoques que enfatizavam o "exótico" no cinema não-europeu.

Diferentemente de sua rival, Positif possuía uma equipe mais coesa, situação facilitada pela não existência de um redator-chefe (a revista era editada por um

\footnotetext{
15 Eram os "jovens turcos", considerados por seus opositores como crítico "reacionários": Alexandre Astruc, Jean-Charles Tacchella, Jacques Donio-Valcroze, Pierre Kast e Claude Mauriac. Ver Les Cahiers Du Cinéma: histoire d'une revue. Paris: Cahiers Du Cinéma, 1991, 2 volumes. NúÑEZ, F. Op. Cit., pp.147- 153 .
}

${ }^{16}$ NÚÑEZ, F. Op. Cit., pp. 164; 168. 
"colegiado") ou de uma hierarquia interna muito demarcada, como havia em Cahiers. Paradoxalmente, nos momentos de "crise" de Cahiers, ainda que Positif se mantivesse como uma revista declaradamente "de esquerda", procurou sutilmente enfatizar determinadas abordagens para arrebanhar o público leitor despolitizado, tradicionalmente leal à concorrente. As discussões em torno do cinema surrealista, do erotismo no cinema - caso dos filmes que exploravam o amour-fou (amor louco), em moda na época - por exemplo, se somavam aos ensaios marcados pelo apoio às lutas colonialistas e às denúncia contra a alienação, o sectarismo e o clericalismo no meio cinematográfico $^{17}$. De toda forma, querelas e paroxismos à parte, em ambas notamos um "latino-americanismo", já atestado por alguns autores, que se inicia no final dos anos sessenta e se encerra por volta de 1974. (BALDELLI, pp. 23; 31)

Atravessando fases mais ou menos politizadas, em suas histórias, poderíamos dizer que o interesse de Cahiers e de Positif pela América Latina tinha seus limites e as abordagens eram movidas pelas problemáticas que atingiam fundamentalmente o meio cinematográfico francês, como as discussões em torno do cinema moderno, os impasses e vantagens do cinema de autor diante das demandas políticas contemporâneas (isto é, a "problemática da ideologia", conforme expressão de época) as discussões sobre semiologia, psicanálise, estruturalismo, dentre outros temas esmiuçados por Fabián Núñez em sua tese. (NÚÑEZ, 2009, caps. III e IV)

Assim, notamos, nessas publicações, que há pouca noção da diversidade existente no continente e uma percepção superficial da autonomia (precária e variável, em termos de liberdade de criação) dos cineastas latino-americanos. Estes, em geral, em ambos periódicos, eram cobrados de que se dedicassem mais a desenvolver projetos individuais e definissem seu estilo pessoal, na perspectiva do cinema "de autor", na contramão do surgimento espontâneo de agrupamentos de cineastas, que ocorriam na América Latina e do qual são exemplos os grupos Ukamau (Bolívia), Cine Liberación (Argentina) ou Cinemateca del Tercer Mundo (Uruguai).

Um nítido interesse que movia essas revistas ao abordarem o cinema da América Latina era o de reforçar a importância do modelo francês e de seu próprio papel, naquele momento, como uma espécie de arauto dessa cinematografia oprimida. Como deduz Julie Amiot-Guillouet, a chamada "onda latino-americana" que arrebanhou o público e a

\footnotetext{
${ }^{17}$.Idem, p. 160.
} 
crítica franceses derivou mais das inquietações vividas por eles mesmos que de um interesse real pelo "outro". Tanto foi assim que a América Latina praticamente desapareceu das páginas das revistas em meados dos anos 1970 (principalmente no caso de Cahiers), diluindo-se em artigos amplos que comentavam o cinema do Terceiro Mundo presente nesse ou naquele festival, ou reaparecendo quando havia algum marco celebrativo, numa atitude memorialista ${ }^{18}$. Por outro lado, é preciso ressaltar que, ao longo da década de setenta, o aparecimento de trabalhos que criticavam o chamado terceiro-mundismo também colaborou para esse esmorecimento do entusiasmo francês. ${ }^{19}$

Evidentemente essa brevidade do interesse pela cinematografia latino-americana deve ser compreendida levando-se em conta que as motivações e a realidade do meio cinematográfico francês, seus temas de debate e preocupações eram de natureza muito distintas, e tributárias de uma tradição consolidada pelas reflexões teórico-estéticas, principalmente. Assim, é compreensível o fato de que as revista dediquem muito mais espaço às problemáticas nacionais. Além disso, mesmo quando o assunto era o cinema chamado "político" ou "de combate", como se usava na América Latina, Cahiers e Positif não se mostravam muito entusiasmadas com as reflexões teóricas em voga a esse respeito.

Positif defendia que "todo cinema era necessariamente político". Essa posição se vincula, em certa medida, ao marxismo de Louis Althusser que influenciou as teorias de cinema, na França, contribuindo para a difusão da idéia de que o cinema político, simplesmente, “é aquele que desnuda os seus próprios mecanismos de produção, encarando o filme como um conjunto de imagens e sons, articulados por uma intenção significante". (NÚÑEZ, 2009, p. 306)

Essas definições de cinema político, algumas muito genéricas, outras vinculadas ao estruturalismo, não tinham boa acolhida na América Latina, uma vez que aqui se entendia por cinema político, na maioria dos países, o essencialmente de esquerda, "de combate", "revolucionário", que espelhasse e estimulasse a militância política. Alguns

\footnotetext{
${ }^{18}$ AMIOT-GUILLOUET, Julie. "Accords et dissonances 'les cinémas latino-américains et les Cahiers du Cinéma (1951-2003). Caravelle - Cahiers du Monde Hispanique et luso-bresilien, Toulouse, núm. 83. Unoversité de Toulouse - le Mirail, 2004, pp. 43-61.

19 Livros que criticam as "teorias de libertação nacional" e a onda terceiro-mundista na França: CHALIAND, G. Mitos revolucionários do Terceiro Mundo. Trad.: Antonio Monteiro Guimarães. Rio de Janeiro: Livraria Francisco Alves, 1977; BRUCKNER, P. Le sanglot del'homme Blanc: Tiers-Monde, culpabilité, haine de soi. Paris: Seuil, 2002. Apud NÚÑEZ, F. Op. Cit., p. 52
} 
autores tentaram demarcar as características desse conceito de "cinema político" na América Latina, diferenciando-o da concepção européia. Afirmam, em defesa da peculiaridade do cinema político latino-americano, que este seria também autoral, além de mesclar referências muito mais díspares no cenário europeu que no latino-americano, como a Nouvelle Vague e o Cinema Verdade ${ }^{20}$.

A principal crítica feita a esse cinema latino-americano "militante", pelos franceses que tendiam a conceber o cinema político num plano mais abrangente, era o discurso fácil, panfletário, demagógico e sem aprofundamento, que muitas vez marcava as obras assim denominadas por seus realizadores. Reivindicavam, portanto, para o cinema político, maior sutileza e cuidado com a estética, em nome da qualidade artística. Brecht muitas vezes era lembrado, na crítica francesa, como autor que poderia inspirar uma forma de cinema político que escapasse do panfleto simplista. Do lado oposto, os defensores do cinema "revolucionário" (Miguel Littín, Julio García Espinosa, Fernando Solanas), no final dos anos sessenta, alegavam a importância da eficácia da mensagem, acima de tudo. O documentarista cubano Santiago Alvarez, por exemplo, assumia com orgulho que pretendia fazer exatamente propaganda política da Revolução, através de seus filmes (LABAKI, 1994).

Cahiers e Positif não poupavam críticas aos debates sobre "cinema político", tão frequentes nos encontros, festivais e mostras, dos dois lados do Atlântico, naquele momento. Estes eram considerados improdutivos ou marcados pelo excesso de verborragia que constava dos discursos dos cineastas militantes. Em relação ao Festival de Pesaro de 1970 (Itália), por exemplo, redatores da Positif lamentavam que o entusiasmo dos debates conduzisse indefectivelmente "a nada", tamanha era a confusão e a incoerência resultantes do excesso de verborragia das esquerdas e das brigas entre as diversas revistas italianas que participavam do evento ${ }^{21}$. Havia, assim, da parte francesa, uma perceptível intolerância com os apaixonados (e muitas vezes confusos - há que se admitir) debates que cercavam o tema do "cinema político". Em 1977 ainda vemos comentários desse tipo e uma crítica contundente dirigida aos filmes políticos latino-

\footnotetext{
${ }^{20}$ Apud NÚÑEZ, F. Op. Cit., p. 30. VER: GETINO, Octavio \& VELLEGGIA, Susana. El cine de 'las historias de la revolución'. Buenos Aires:Altamira / Instituto Nacional de Cine y Artes Audiovisuales, 2002.

${ }^{21}$ ARLORIO, Piero e SEGUIN Louis. "La guerrilla de la salive (Pesaro en 1970)”. Positif núm. 122, décembre 1970, pp. 27-38.
} 
americanos: segundo a revista, estes pecavam pela superficialidade da análise da situação política do país e da ideologia vigente, e construíam geralmente um discurso contra uma espécie de "inimigo invisível"22.

De fato, o discurso dos cineastas e críticos latino-americanos era bastante marcado pelo combate ao inimigo comum, nada invisível nas regiões central e sul do continente: os EUA, e de forma mais ampla, ao imperialismo. No Festival de Viña del Mar, no Chile, em 1969, um dos debates realizados intitulava-se exatamente "Imperialismo e Cultura. O cinema como instrumento revolucionário". Nessa ocasião, uma discussão acirrada se formou entre o cineasta chileno Raul Ruiz, conhecido por seus filmes alegóricos e formalistas que tiveram ótima acolhida na França (onde, inclusive, esse cineasta se radicou), e os cineastas argentinos simpatizantes do modelo de documentário sugerido por La hora de los hornos, o "filme-ato", acusados por Ruiz de apenas repetirem lugares comuns ${ }^{23}$ (FRANCIA, 1990, p.168).

No âmbito dos festivais europeus, Positif fez a cobertura, por exemplo, de um caloroso debate que houve durante o Festival de Pesaro, em 1973, opondo o crítico Jean Marie Straub ao cubano Tomás Gutiérrez Alea, ao brasileiro Glauber Rocha e outros cineastas latino-americanos, a respeito da má qualidade dos roteiros dos filmes políticos na América Latina e ao fato de muitos deles imitarem modelos hollywoodianos de narrativa e condução da trama ${ }^{24}$. A essa crítica do francês, os cineastas cubanos argumentaram que "o cinema era uma arma”, e que tudo seria válido no combate contra o inimigo. Nessa ocasião, apesar da revista nunca ter afirmado proposições semelhantes, se posicionou de forma simpática - e politicamente solidária - aos latino-americanos. Mesmo não endossando o combativismo radical dos cineastas latino-americanos, a equipe editorial da revista ridicularizou a postura de Straub e chegou a descrever de forma muito irônica, em 1977, seu filme Toute révolution es un coup de dés, descrito como uma conversa pretensiosa e banal de um grupinho de amigos tomando sol e recitando Mallarmé ${ }^{25}$.

Segundo alguns autores, nos debates sobre o "cinema político", dessa época, delineiam-se, simplificadamente, duas grandes vertentes: uma defensora do "cinema

\footnotetext{
${ }^{22}$ CODELLI, Lorenzo. "Festival de Pesaro 1977”. Positif, núm. 205, avril 1978, pp. $45-47$.

${ }^{23}$ Ver: FRANCIA, Aldo. NCL en Viña del Mar. Santiago: Artecien / CESOC, 1990, p. 168.

${ }^{24}$ SEGUIN, Louis. "Le Festival et le commentaire (II)”. Positif núm. 158, avril 1974, pp. 65-67.

${ }^{25}$ COLDELLI, Lorenzo. “Festval de Pesaro 1977”. Positif núm. 205, avril 1978, pp. 45-47.
} 
panfletário" e outra defensora do "cinema alegórico"26 (MARROSU, 1970; NÚÑ̃EZ, 2009, p. 362). Entretanto, tal bipolarização deve ser matizada em alguns casos, pois, como demonstra Núñez, as equipes editoriais das revistas de cinema da América Latina, em geral não defendiam um modelo único para o $N C L$ e muitas vezes, se manifestavam, como a crítica francesa, contra o discurso fácil, panfletário. Nas revistas Hablemos del Cine (Peru) e Cine al Día (Venezuela), por exemplo, um filme considerado "político" e citado como contraponto louvável a La hora del los hornos, é o brasileiro Macunaíma (1969), de Joaquim Pedro de Andrade. ${ }^{27}$

A forte rejeição, pela crítica francesa, ao discurso panfletário, deve ser compreendida não apenas considerando os fatores políticos, mas a própria cultura cinematográfica daquele país, uma vez que esse tipo de linguagem não fazia parte de sua tradição cinematográfica, como já salientamos. Além disso, a força da tradição do cinema francês, e o próprio histórico do país como "império" contribuíam para que a crítica priorizasse a produção nacional, os temas nacionais, havendo pouco espaço para a abordagem de temas do "Terceiro mundo". Um número especial de Positif dedicado à política, por exemplo, em fevereiro de 1970 (o Dossiê "La Politique. Thése, Débat, Entretien", núm. 113) trata especificamente de questões relacionadas ao contexto francês do momento e se não fosse por um artigo dedicado ao filme La hora de los hornos, os problemas latino-americanos, estariam praticamente ausentes desse dossiê.

Num outro momento, a equipe de Positif, ao ser convidada a escolher quatro filmes exemplares do "cinema político", em 1971, não elege nenhum filme "do Terceiro Mundo" em tal seleção. Defendendo a tese de que "todo cinema é político" e que a escolha recaía sobre alguns em que a discussão aparecia de forma privilegiada, não importando a tendência ideológica em questão, a revista selecionou um filme fascista, L'Homme a la Croix; um francês Déjeuner sur l'herbe; um norte-americano, The

\footnotetext{
${ }^{26}$ A crítica Ambreta Marrossu classifica as duas vertentes do cinema chileno daquele período como cinema "de intervenção pollítica" e "alegórico". MARROSSU, Ambretta. "Viña del Mar: segundo festival de cine latino". Cine al Dia, Caracas, núm. 9, mar 1970, pp. 20-21. Apud NÚÑEZ, F. Op. Cit., p. 362.

${ }^{27}$ O autor cita a crítica do argentino J. A. Mahieu aos "revolucionários de festival" em "Retórica cinematográfica o retórica revolucionaria", Cine \& Medios, Buenos Aires, núm. 3, 1970, pp. 36-37 e um texto de Isaac Leon Frias na revista peruana Hablemos de Cine, 1969/70, p. 26, no qual distingue "cinema de intervenção política" de "cinema político". Considera um dos melhores artigos de época sobre essa questão, que envolve problematizações da relação entre forma e conteúdo, o artigo ROFFÉ, A. "Problemas de la elaboración”. Cine al Dia, núm. 6, deciembre 1968, pp. 10-15. Idem, pp. 364-370.
} 
Manchurian candidate e um soviético Le Premier Maitre como casos "exemplares" desse tipo de expressão. ${ }^{28}$

Cabe destacar que na França, a idéia representada pela metáfora do "cinema como arma", tão popular na América Latina, apesar de ter conquistado espaço após Maio de 68 nunca convenceu verdadeiramente a maior parte da crítica especializada, uma vez que essa idéia pressupunha uma visão utilitarista do cinema e os franceses sempre se mostraram muito ciosos da visão do cinema como arte, defendendo que o cinema deveria ser uma arma "em si mesmo".

Assim como Cahiers, Positif sempre demonstrou clara preferência pelo Cinema Novo e dentre os cineastas brasileiros, dedicou muitos artigos a Ruy Guerra (principalmente seus filmes Os fuzis, Os Deuses e os Mortos e A Queda, alvos de elogios rasgados em diversos artigos) ${ }^{29}$. Podemos afirmar que a revista, em se tratando de cinema brasileiro, após aparentar ter sofrido uma decepção, no final dos anos sessenta, com os rumos das produções de Glauber, alça Ruy Guerra à condição de "cineasta genial" antes ocupada pelo baiano. Além deste, Nelson Pereira dos Santos também merece lugar no panteão dos bons realizadores latino-americanos (Como era gostoso o meu francês, exibido em Cannes, em 1971, é bastante elogiado pela revista) ${ }^{30}$.

As duas revistas tratam da produção cinematográfica latino-americana pelo prisma da questão autoral. Não há, portanto, como no caso das revistas latinoamericanas, a menção ao movimento NCL de forma explícita. No dossiê de Positif dedicado à América Latina, por exemplo, em dezembro de 1974, lemos na capa "Amérique latine: Brésil, Chili, Bolivie". Assim, o enfoque é direcionado basicamente às cinematografias nacionais e, dentro delas, aos cineastas especificamente dignos de serem abordados. Ainda que reconheça em suas obras alguma pretensão de fomentar

\footnotetext{
${ }^{28}$ Essa seleção foi feita por outras três revistas francesas ; Les Cahiers du Cinéma, Cinéma 71, Cinéthique, durante a VI Mostra Internazionale del Cinema Libero di Porretta Terme e publicada no texto "Quatre propositions de Cinéma Politique". Ver: "La politique et le cinéma, et la politique". Positif, núm. 132, novembre 1971, pp. 59-62.

${ }^{29}$ PARANAGUÁ, P. "Ruptures et continuité. Á propos de La Chute de Ruy Guerra et Nelson Xavier". Positif, núm. 228, mars 1980, pp. 10-15.

30 Diversos outros cineastas brasileiros aparecem em reportagens da revista. Há tanto elogios como críticas em relação aos filmes considerados "tropicalistas" pela revista. Pindorama, de Arnado Jabor, exibido em 197i, em Cannes, é execrado, assim como Xica da Silva, de Cacá Diegues, em 1977, enquanto Iracema (Jorge Bodanzki) e Gitirana (Orlando Senna) ganham avaliações positivas em 1976 (por mesclarem documentários, cinema verité e ficção), bem como Bye Bye Brasil. Ver: AMENGUAL, Barthélemy, et al."Festival de Cannes". Positif, núm. 195-196, juillet-aout 1977, p. 87; AMENGUAL, Barthélemy, et al.”Cannes 1976". Positif, núm. 183-184, juillet-aout 1976, p. 92.
} 
uma identidade coletiva ou um "cinema de luta continental", parafraseando as palavras publicadas pela própria revista, não é essa a ênfase conferida pela reportagem.

Nesse sentido, a crítica cinematográfica é individualizada, e podemos inclusive acrescentar que pouco se informa a respeito da cinematografia nacional a qual ela se vincula. Os filmes do boliviano Jorge Sanjinés (idealizador do grupo Ukamau) geralmente são elogiados pela plasticidade (beleza formal, ainda que austera), pela nobreza da escolha temática. Entretanto, há crítica aos usos de chavões e à presença de elementos caricaturais. Vale ressaltar que esses são problemas também identificados com frequência nas produções cubanas; caso de El Brigadista de Octavio Cortázar ${ }^{31}$, El recurso del método do chileno Miguel Littín ${ }^{32}$, e Una mujer, un hombre, una ciudad de Manuel Octavio Gómez ${ }^{33}$. Nitidamente, nesses artigos de Positif, vemos que a revista opta por celebrar o subjetivismo, o lirismo, ao didatismo. Isso permanece por toda a década de setenta, e um artigo de 1981 celebra filmes que são considerados "de combate" porém líricos ou míticos (são citados Bye Bye Brasil, de Cacá Diegues, Los Hijos de Fierro, de Solanas e La Viuda Montiel, de Miguel Littín) ${ }^{34}$. Ao comentá-los, o crítico ressalta que, em comparação com os anos 60 , houve um significativo abandono da audácia formal, mas ganhou-se em lirismo. Além disso, todos esses filmes teriam em comum, positivamente, a presença de personagens simbólicos e de algum nível de reflexão sobre a identidade latino-americana, ainda que fossem voltados a temáticas nacionais.

A partir de meados dos anos 70, Positif passou a contar com colaboradores especializados em cinema latino-americano, caso de Zuzana Myriam Pick (a partir de 1974) e o brasileiro Paulo Paranaguá (a partir de 1978). Ambos são hoje autores de estudos referenciais sobre o $N C L$. Essa presença garantiu artigos mais extensos e de qualidade, geralmente focando aspectos da história das cinematografias latinoamericanas. Positif publicou um dossiê sobre a América Latina em dezembro de 1974 (núm. 164) e a partir desse número, vários outros artigos, assinados por um ou outro,

\footnotetext{
${ }^{31}$ AMENGUAL, B. \& JORDAN, Isabelle. "Festival de Berlin 1978". Positif, núm. 207, juin 1978, pp. $52-57$.

32 AMENGUAL, Barthélemy, et al. "Le Festival de Cannes 1978”. Positif, núm. 208-209, juillet-aout 1978, p.98.

${ }^{33}$ Idem, pp. 99-102.

${ }^{34}$ POUILLADE, Jean-Luc. "Terras en Transes. Les Fils de Fierro, La Veuve Montiel , Bye Bye Brèsil". Positif núm. 242, mai 1981, pp. 32-36.
} 
sobre as histórias dos cinemas mexicano (artigo de Pick, em março 1974; e de Paranaguá, em março de 1984), chileno (dois artigos de Pick, em janeiro de 1974 e em dezembro de 1983) e argentino (artigo de Paranaguá, de setembro de 1985). Além disso, Paranaguá ficou encarregado de boa parte das resenhas críticas dos filmes latinoamericanos, na cobertura do Festival de Cannes, a partir de 1978, e dos demais festivais que foram surgindo, ao longo dos anos 1980, dedicados a América Latina, como o festival de Biarritz (a partir de 1979).

Uma das questões interessantes que se revelaram no decorrer de nossa pesquisa, foi compreender o descompasso entre o aumento de espaços de difusão do cinema latino-americano na França e a diminuição dos artigos sobre cinema latino-americano em Cahiers e Positif. No final dos anos setenta, parece que a "onda latino-americanista" contagia os espaços culturais alternativos franceses, mas tal profusão não repercute numa incidência maior dessa cinematografia nas revistas francesas. Ao contrário, há uma diminuição de artigos voltados ao cinema da América Latina. O que podemos supor é a existência de certo grau de independência dos dois universos (o da crítica e o dos eventos), e o predomínio de dinâmicas não necessariamente consoantes. De toda forma, essa questão mereceria um estudo mais aprofundado, que leve em conta a política cultural francesa e fatores intrínsecos à dinâmica do meio cinematográfico, como a lógica do mercado e de distribuição de filmes na Europa. 


\section{Bibliografia}

AMENGUAL, Barthélemy, et al.’Festival de Cannes". Positif, núm. 195-196, juilletaout 1977, p. 87; AMENGUAL, Barthélemy, et al.”Cannes 1976”. Positif, núm. 183184, juillet-aout 1976, p. 92.

AMENGUAL, B. \& JORDAN, Isabelle. "Festival de Berlin 1978”. Positif, núm. 207, juin 1978, pp. 52-57.

AMENGUAL, Barthélemy, et al. "Le Festival de Cannes 1978”. Positif, núm. 208-209, juillet-aout 1978, p.98.

AMIOT-GUILLOUET, Julie. “Accords et dissonances 'les cinémas latino-américains et les Cahiers du Cinéma (1951-2003). Caravelle - Cahiers du Monde Hispanique et lusobresilien, Toulouse, núm. 83. Unoversité de Toulouse - le Mirail, 2004, pp. 43-61.

ARLORIO, Piero e SEGUIN Louis. "La guerrilla de la salive (Pesaro en 1970)". Positif núm. 122, décembre 1970, pp. 27-38.

\section{BALDELLI}

CODELLI, Lorenzo. "Festival de Pesaro 1977”. Positif, núm. 205, avril 1978, pp. 4547.

GETINO, Octavio \& VELLEGGIA, Susana. El cine de 'las historias de la revolución'. Buenos Aires:Altamira / Instituto Nacional de Cine y Artes Audiovisuales, 2002.

HULEC, Jean-René; RAMONET, Ignacio et TOUBIANA, Serge. "Entretien avec Jorge Sanjinés". Cahiers du Cinéma, num. 253.

“La politique et le cinéma, et la politique”. Positif, núm. 132, novembre 1971, pp. 5962.

Les Cahiers Du Cinéma: histoire d'une revue. Paris: Cahiers Du Cinéma, 1991, 2 volumes. 
LABAKI, A. O olho da Revolução - o cinema urgente de Santiago Alvarez. São Paulo: Iluminuras, 1994

LIMA, Monica. Cinema e revolução na Argentina: Grupo Cine Liberación (19661971).

Marcorelles, Louis. Cahiers du Cinéma, núm. 210, mars 1969, p. 39.

MENDONÇA, Mary Enice Ramalho de. História e Cinema: cinemanovismo e violência na América Latina. Décadas de sessenta e setenta. Tese de Livre Docência, São Paulo, ECA-USP, 1995, 2 volumes.

NÚÑEZ, Fabián Rodrigo Magioli. O que é Nuevo Cine Latinomaericano? O cinema moderno na América Latina segundo as revistas cinematográficas especializadas latino-americanas. Niterói, Tese de Doutorado, UFF, 2009.

PARANAGUÁ, Paulo Antonio. Cinema na América Latina: longe de Deus e perto de Hollywood. Porto Alegre: L\&PM, 1985.

. Le cinéma en Amérique Latine: le miroir éclaté. Historiographie et comparatisme. Paris: L'Harmattan, 2000.

PARANAGUÁ, P. "Quelques films ibériques et latino-américains, vus à Biarritz ou ailleurs". Positif, núm. 228, mars 1980, p. 58-63

PARANAGUÁ, P. "Ruptures et continuité. Á propos de La Chute de Ruy Guerra et Nelson Xavier”. Positif, núm. 228, mars 1980, pp. 10-15.

PICK, Z. The New Latin American Cinema, a Continetal Project. Austin: University of Texas Press, 1996.

PRADO, Maria Lígia. "Identidades latinoamericanas" in Historia General de América Latina, Vol. VII. Paris: Ediciones UNESCO, 2008, pp. 583-615.

RUEDA, Amanda. "Films latino-américains, festivals français". Caravelle, Univ. de Toulouse, núm. 83, 2004, pp. 87-104

SEGUIN, Louis. "Le Festival et le commentaire (II)”. Positif núm. 158, avril 1974, pp. 65-67. 
SIRINELLI, Jean-François. “Os intelectuais”, in RÉMOND, René (org). Por uma história política.Trad. Dora Rocha. Rio de Janeiro: UFRJ/FGV, 1996, pp. 242-269.

THIRARD, Paul-Louis. "Positif, sa quinzaine, la distribution et la censure". Positif, núm. 103, mars 1969, pp. 52-54.

TOUBIANA, Serge. “Le pouvoir parlé”.Cahiers du Cinéma, septembre 1974, p. 23. 